\title{
Cognition, Comprehension and Application of Biostatistics in Research by Postgraduate Medical Students of a Tertiary Care Teaching Hospital: Pretest and Posttest Study Design
}

\author{
${ }^{1}$ Rajaat Vohra, ${ }^{2}$ Siddharth Pramod Dubhashi, ${ }^{3}$ Bhoopendra Nath Sharma, ${ }^{4} \mathrm{GN}$ Saxena, ${ }^{5}$ Anusha Vohra
}

\begin{abstract}
Introduction: Biostatistics plays a key role in planning, conduct, analysis and reporting of a research. Teaching biostatistics and research methodology is often considered as a difficult task to medical students. The present study was undertaken to evaluate the cognition, comprehension and application of biostatistics in research in the 1st year postgraduate medical students.
\end{abstract}

Materials and methods: A predesigned and pretested questionnaire was used to collect data regarding knowledge and application of biostatistics from 65 postgraduate students registered. A series of 10 lectures were taken on various topics of biostatistics and research methodology. All students were subjected to Multiple Choice Questions covering all the topics before the 1st lecture and after the 10th lecture. Mean knowledge score was calculated and data were analyzed.

Results: Only $16.92 \%$ students had publication, $35.38 \%$ students have presented a paper/poster in any national or international conference while only $10.76 \%$ students have participated in any research methodology workshop. A total of $63.07 \%$ students said that they were aware of importance of biostatistics in research, $50.76 \%$ students said that they were having some knowledge of biostatistics. A total of $60 \%$ students have consulted statistician regarding the study while $23.07 \%$ students have attempted statistical analysis on their own. A total of $33.84 \%$ students are familiar with the use of MS-EXCEL spreadsheet. There was statistically significant improvement seen in the mean knowledge score of the students after the lectures in comparison to the mean knowledge score before the lectures.

Conclusion: Considering the fruitful outcome of structured training program in biostatistics, there is a need for provision of formal training in biostatistics to postgraduate students in all medical colleges. Capacity building initiative in this domain is the need of the hour.

\footnotetext{
${ }^{1,5}$ Associate Professor, ${ }^{2}$ Director, Professor and Unit Head ${ }^{3}$ Professor and Head, ${ }^{4}$ Principal and Professor

${ }^{1,3}$ Department of Community Medicine, Mahatma Gandhi Medical College and Hospital, Jaipur, Rajasthan, India

${ }^{2}$ Academics and Student Affairs, Department of Surgery Mahatma Gandhi Medical College and Hospital, Jaipur Rajasthan, India

${ }^{4}$ Department of Medicine, Mahatma Gandhi Medical College and Hospital, Jaipur, Rajasthan, India

${ }^{5}$ Department of Pharmacology, Mahatma Gandhi Medical College and Hospital, Jaipur, Rajasthan, India

Corresponding Author: Rajaat Vohra, D-4, Ganesh Marg Bapu Nagar, Jaipur, Rajasthan, India, Phone: +91 9660500686 0141-4050827, e-mail: drrajatvohra@gmail.com
}

Keywords: Application, Biostatistics, Knowledge, Postgraduate medical students, Research methodology.

How to cite this article: Vohra R, Dubhashi SP, Sharma BN, Saxena GN, Vohra A. Cognition, Comprehension and Application of Biostatistics in Research by Postgraduate Medical Students of a Tertiary care Teaching Hospital: Pretest and Posttest Study Design. J Mahatma Gandhi Univ Med Sci Tech 2016;1(1):5-9.

\section{Source of support: Nil}

Conflict of interest: Nil

\section{INTRODUCTION}

Biostatistics can be defined as "The science of statistics applied to the analysis of biologic or medical data". It is an integral part of clinical research process and plays a crucial role in planning, conduct, analysis, and reporting of clinical trial. ${ }^{1}$ Biostatistics includes epidemiology, design and analysis of clinical trials in human and veterinary medicine, population genetics, biological sequence analysis, ecology, etc. People who are working in scientific research, in order to share their work with the scientific community, find it mandatory to apply concepts of biostatistics into their work. ${ }^{2}$

In a medical education system, health research training is a fundamental and essential component. ${ }^{3}$ In recent times, health institutions in South Asia are getting more apprehension about lack of research activities among medical students and because of this there is increase in academic research programs among medical professionals in these countries. Numerous guidelines and policies have been formulated and implemented like including compulsory and optional research assignments, inclusion of student sections in indexed journals, organizing scientific conferences especially for students, shaping of medical prospectus and curriculum to assimilate capacity building programs for research and organization of workshops on different aspect of research. ${ }^{4-6}$

A good understanding of biostatistics and epidemiology can improve clinical decision-making, program evaluation and medical research with regard to both individuals and groups of people. ${ }^{7}$ In more 
than 500 medical colleges across the country, several dissertation and research are being completed which require application of biostatistics ranging from simple descriptive analysis to complicated, multifactorial comparisons, and correlations. The postgraduate medical student very rarely performs the statistical analysis by himself, mostly done by a qualified statistician. Thus, the present study was undertaken to evaluate the cognition, comprehension and application of biostatistics in research in the 1st year postgraduate students of Mahatma Gandhi Medical College, Jaipur.

\section{AIMS AND OBJECTIVES}

- To evaluate the cognition, comprehension and application of biostatistics in research for the 1st year postgraduate medical student.

- To evaluate the effectiveness of training in biostatistics for the postgraduate medical students.

\section{MATERIALS AND METHODS}

The present study was carried out among 1st year postgraduate medical students who were admitted to the Doctor of Medicine (MD)/Master of Surgery (MS) course at Mahatma Gandhi University of Medical Sciences and Technology, Jaipur, from October 2015 to December 2015. The study was approved by the Institute Review Board.

A total 65 postgraduate students participated in the study. A predesigned and pretested validated questionnaire was used to collect the information regarding the level of knowledge of biostatistics and research, understanding and its application in design and conduct of the research protocol, involvement in research other than dissertation, presentation of paper/poster in national or international conferences and involvement in workshops. The questionnaire was subjected to a thorough peer review by four senior faculties of various specialities of the medical college. The questionnaire was also piloted among 10 postgraduate students and modified as per the suggestions obtained.

A series of 10 lectures were taken on biostatistics by the faculty member from October 2015 to December 2015, twice a week, on every Wednesday and Friday, on the following topics:

- Introduction, variables, types of variables, data presentation

- Normal distribution curve, measures of central tendency, measures of dispersion

- Sampling, types of sampling, estimation of sample size

- Types of epidemiological studies, descriptive epidemiology
- Case control and cohort study

- Randomized controlled trial

- Tests of significance:

- Chi-square test

- Unpaired and paired t-test

- ANOVA

- Correlation and regression

- Sensitivity, specificity, positive predictive value (PPV), negative predictive value (NPV).

- Use of computers in biostatistics: Microsoft Excel and SPSS.

All students were subjected to Multiple Choice Questions covering all the topics before the 1st lecture and after the 10th lecture to evaluate the knowledge and application of biostatistics in research. For every student, the percentage of correct multiple choice answers was calculated as a representative of knowledge score.

The data were entered in Microsoft Office Excel sheet, paired t-test was used to compare the mean knowledge attitude scores before and after the lectures. A p value less than 0.05 was considered to be statistically significant.

\section{RESULTS}

In the present study as shown in Table 1, out of 65 postgraduate students, only $11(16.92 \%)$ had any publication, $23(35.38 \%)$ students have presented a paper/poster in any national or international conference while only 7 (10.76\%) students have participated in any research methodology workshop. A total of 41 (63.07\%) students said that they were aware of importance of biostatistics in research, $33(50.76 \%)$ students said that they were having some knowledge of biostatistics. A total of 51 (78.23\%) students think that knowledge about biostatistics is a must for PG trainee while 32 (49.23\%) think undertaking research increases the burden of postgraduate students.

In the present study, 48 (73.84\%) students have conducted a study requiring statistical analysis, 39 (60\%) have consulted statistician regarding the study. Only $15(23.07 \%)$ students have attempted statistical analysis on their own while 22 (33.84\%) students are familiar with the use of MS-EXCEL spreadsheet for graphical representation of data (Table 1 and Graph 1).

Table 2 shows the mean knowledge score of the 1st year postgraduate students before and after the lectures. There was statistically significant improvement seen in the mean knowledge score of the students after the lectures in comparison to the mean knowledge score before the lectures.

The mean knowledge score of the students after the lecture on biostatistics was 6.61 which was considerably higher in comparison to the mean score before the lecture (Graph 2). 


\begin{tabular}{|c|c|c|c|}
\hline SI. no. & Questions & $\begin{array}{c}\text { Yes } \\
n(\%)\end{array}$ & $\begin{array}{c}\text { No } \\
n(\%)\end{array}$ \\
\hline 1. & Do you have any publication? & $11(16.92)$ & $54(40.89)$ \\
\hline 2. & Have you ever presented a paper in any national or international conference? & $23(35.38)$ & $42(64.61)$ \\
\hline 3. & Do you read journals regularly? & $37(56.92)$ & $28(43.07)$ \\
\hline 4. & Have you participated in research methodology workshop? & $7(10.76)$ & $58(89.23)$ \\
\hline 5. & Are you aware of the importance of biostatistics in research? & $41(63.07)$ & $24(36.92)$ \\
\hline 6. & Have you ever conducted a study requiring statistical analysis? & $48(73.84)$ & $17(26.15)$ \\
\hline 7. & Do you have some knowledge of biostatistics? & $33(50.76)$ & $32(49.23)$ \\
\hline 8. & Do you consult a statistician regarding your study? & $39(60)$ & $26(40)$ \\
\hline 9. & Do you participate in the statistical analysis of your study along with statistician? & $29(44.61)$ & $36(55.38)$ \\
\hline 10. & Is biostatistics a part of your curriculum? & $42(64.61)$ & $23(35.38)$ \\
\hline 11. & Did you ever attempt to perform statistical analysis for a study on your own? & $15(23.07)$ & $50(76.92)$ \\
\hline 12. & Are you familiar with use of MS-EXCEL spreadsheet for graphical representation of the data? & $22(33.84)$ & $43(66.15)$ \\
\hline 13. & Do you think knowledge about biostatistics is a must for PG trainee? & $51(78.46)$ & $14(21.53)$ \\
\hline 14. & What do you think, undertaking research increases burden of postgraduate student? & $32(49.23)$ & $33(50.76)$ \\
\hline
\end{tabular}

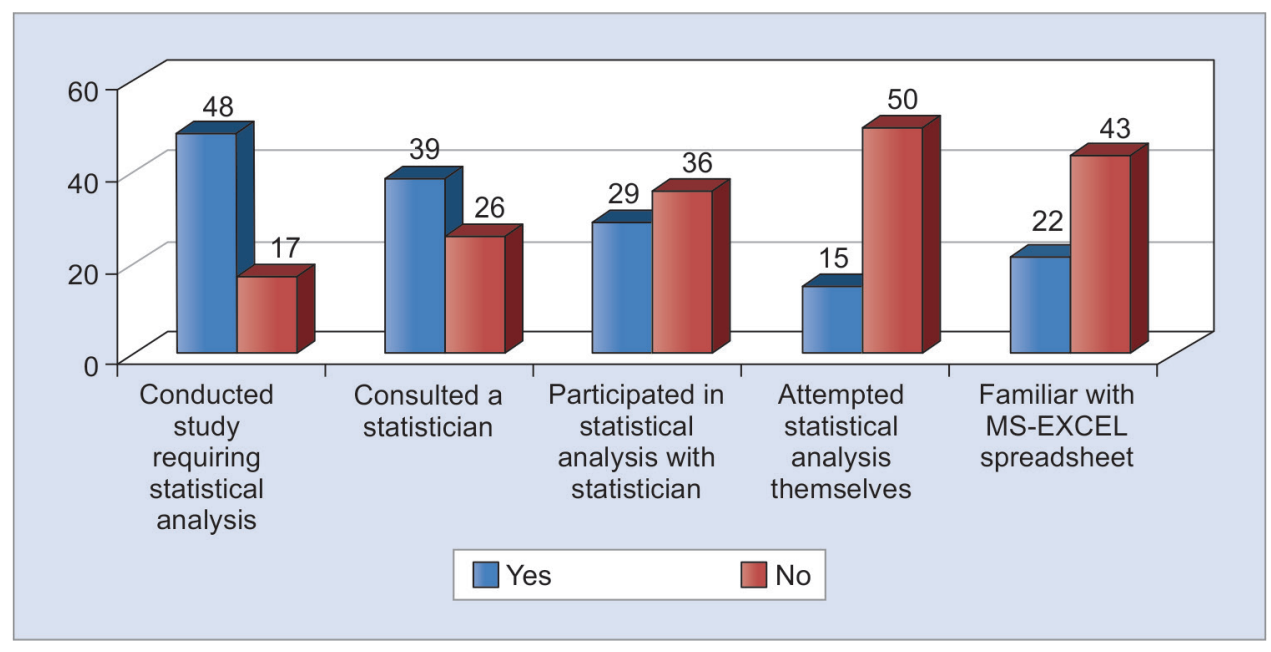

Graph 1: Application of biostatistics in research by postgraduate medical students

Table 2: Mean knowledge score before and after the lectures

\begin{tabular}{llll}
\hline & $\begin{array}{l}\text { Pretest correct } \\
\text { knowledge } \\
\text { Mean (SD) }\end{array}$ & $\begin{array}{l}\text { Posttest correct } \\
\text { knowledge } \\
\text { Mean (SD) }\end{array}$ & $p$-value \\
\hline $\begin{array}{l}\text { Introduction, variables, types of variables, data presentation } \\
\text { Normal distribution curve, measures of central tendency, measures of } \\
\text { dispersion }\end{array}$ & $\begin{array}{l}4.97(1.97) \\
\text { Sampling, types of sampling, estimation of sample size }\end{array}$ & $8.74(3.31)$ & 0.000 \\
Types of epidemiological studies, descriptive epidemiology & $3.13(4.01)$ & $6.89(3.97)$ & 0.000 \\
Case control and cohort study & $5.18(3.25)$ & $7.67(4.20)$ & 0.000 \\
Randomized control trial & $2.34(2.79)$ & $4.33(3.65)$ & 0.000 \\
Tests of significance & $3.14(1.16)$ & $5.03(2.69)$ & 0.000 \\
Correlation and regression & $4.44(2.78)$ & $7.89(3.95)$ & 0.000 \\
Sensitivity, specificity, positive predictive value and negative predictive value & $3.17(4.67)$ & $6.19(4.85)$ & 0.001 \\
\hline
\end{tabular}




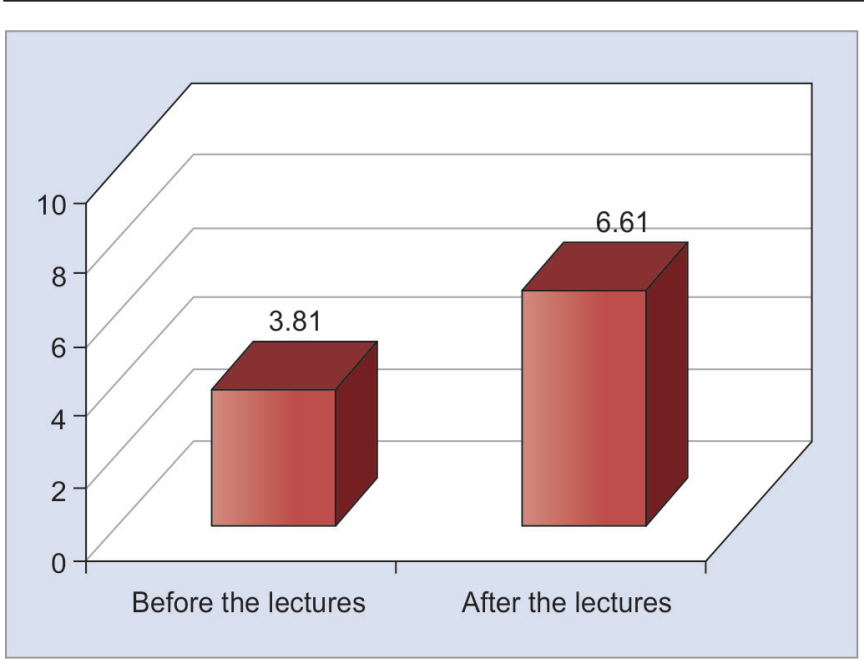

Graph 2: Mean knowledge score of the students before and after the lectures

\section{DISCUSSION}

Teaching biostatistics and research methodology is often considered as a difficult task to medical students. Medical Council of India has made it mandatory for every postgraduate student to present a paper/poster in any national or international conference and to publish a research paper in an Indexed journal. Biostatistics plays a key role in planning, conduct, analysis and reporting of a research, thus every postgraduate student entering into medical institute is now aware of importance of understanding and application of biostatistics. Biostatistics sheds additional light and clarity upon subjects under study. Its proper use converts scientific assumptions into proven facts.

In the present study, only $16.92 \%$ students had any publication, $35.38 \%$ students had presented a paper/ poster in any national or international conference while only $10.76 \%$ students have participated in any research methodology workshop. A study done by Thakre et $\mathrm{al}^{4}$ in Nagpur shows that $42.05 \%$ students had done presentations at various conferences and $9.34 \%$ students had publications. A total of $21.50 \%$ students had participated in research method workshop.

A total of $63.07 \%$ students in the study said that they were aware of importance of biostatistics in research, 50.76\% students said that they were having some knowledge of biostatistics. Windish et $\mathrm{al}^{8}$ have concluded in an American report that almost $75 \%$ of respondents have admitted of not having full knowledge of all statistical procedures reported in medical journals. A total of $78.23 \%$ students think that knowledge about biostatistics is a must for PG trainee while $49.23 \%$ think undertaking research increases the burden of postgraduate students. A study on importance and understanding of biostatistics done by Asif et $\mathrm{al}^{9}$ in
Lahore, Pakistan, states that significant proportion of students agree that biostatistics course is useful to them and every medical institute should start regular courses in biostatistics during MBBS.

In the present study, $48(73.84 \%)$ students have conducted a study requiring statistical analysis, 39 (60\%) have consulted statistician regarding the study. Only $15(23.07 \%)$ students have attempted statistical analysis on their own while $22(33.84 \%)$ students are familiar with the use of MS-EXCEL spreadsheet for graphical representation of data. A study done by Jonnalagadda et $\mathrm{al}^{1}$ in postgraduate students in periodontics shows that $79.2 \%$ students are aware of importance of biostatistics in research, 55 to $65 \%$ were familiar with MS-EXCEL spreadsheet for graphical representation of data and with statistical softwares available on internet, $26.0 \%$ had biostatistics as mandatory subject in their curriculum, 9.5\% tried to perform statistical analysis on their own while $3.0 \%$ were successful in performing statistical analysis of their studies on their own.

There was statistically significant improvement seen in the mean knowledge score of the students after the lectures in comparison to the mean knowledge score before the lectures. A similar study by Des Cruser et $\mathrm{al}^{10}$ in a similar pretest and posttest study also showed significant improvement in applied understanding of concepts after 24 hours of classroom lectures.

A study done by Singh et $\mathrm{al}^{11}$ shows that there is paucity of programs providing specialized training in biostatistics in India. Only about 19 institutions in India are offering various courses in biostatistics/medical statistics/health statistics/biometry. It is important to look into the current capacity building initiatives in this domain. Some other means for giving importance to biostatistics could be by making it a separate branch/specialization in a majority of the institutions, particularly in medical colleges.

\section{LIMITATION OF THE STUDY}

This study involved only 1st year postgraduate medical students of a single medical institution. Thus, the results cannot be generalized. Studies evaluating the long-term impact of such interventions are needed.

\section{CONCLUSION}

Considering the fruitful outcome of structured training program in biostatistics, there is a need for provision of formal training in biostatistics to postgraduate students in all medical colleges. Capacity building initiative in this domain is the need of the hour. 


\section{REFERENCES}

1. Swetha JL, Arpita R, Srikanth C, Nutalapati R. Cognition, comprehension and application of biostatistics in research by Indian postgraduate students in periodontics. J Indian Soc Periodontol 2014 Jan-Feb;18(1):65-68.

2. Heinzmann D. Biostatistics-Where mathematics meets biology. Newsletter YEBN. Nov 2006.

3. Scaria V. Whisking research into medical curriculum: The need to integrate research in undergraduate medical education to meet the future challanges. Calicut Med J 2004;2:e1.

4. Thakre SB, Thakre SS, Golawar SH, Ughade SN, Thakre AD. Awareness about biomedical research among postgraduate students at a tertiary care hospital, central India: Pretestposttest study design. Perspectives in Medical Research. 2014 May-Aug;2(2):8-14.

5. Aslam F, Shakir M, Qayyum MA. Why medical students are crucial to the future of research in South Asia. PLoS Med 2005 Nov;2(11):e322.
6. The PLoS Medicine Editors. Improving health by investing in medical education. PLoS Med 2005 Dec;2(12):e424.

7. Mostert P. Changing approaches and perceptions: Biostatistics and its role in teaching. The Stellenbosch Doctor. ICOTS 2006;7.

8. Windish DM, Huot SJ, Green ML. Medicine residents understanding of biostatistics and results in the medical literature. J Am Med Assoc 2007;298(9):1010-1022.

9. Asif H, Asim B, Awais SM. Importance and understanding of bio-statistics among post graduate students at King Edward Medical University, Lahore- Pakistan. Annals 2009 Jul-Sep;15(3):107-110.

10. Des Cruser A, Brown SK, Ingram JR, Podawiltz AL, Dubin BD, Colston JS, Bulik RJ. Learning outcomes from a biomedical research course for second year osteopathic medical students. Osteopathic Med Primary Care 2010 July;4:4.

11. Singh R, Zodpey SP, Sharma K, Bangdiwala SI, Ughade S. Landscaping biostatistics education in India. Indian J Public Health. 2012 Oct-Dec;56(4):273-280. 